\title{
The Role of Job Search Methods and Contacts on Commuting and Relocation Decisions
}

\author{
Nebiyou Tilahun* $\quad$ David Levinson ${ }^{\dagger}$
}

Submission Date: August 1, 2009

\footnotetext{
*University of Minnesota, Department of Civil Engineering, tila0006@umn.edu

${ }^{\dagger}$ RP Braun-CTS Chair of Transportation Engineering; Director of Network, Economics, and Urban Systems Research Group; University of Minnesota, Department of Civil Engineering, 500 Pillsbury Drive SE, Minneapolis, MN 55455 USA, dlevinson@umn.edu http://nexus.umn.edu
} 


\begin{abstract}
This paper empirically explores the relationship between (i) job finding and commuting outcomes and (ii) the relationship between job search and the commute and location outcomes of relocation decisions after finding employment. The relationship between commute outcomes when finding a new job and the job search method that one employs are explored first. That is followed by an analysis of how long one stays at their residence after finding work, and where they eventually relocate relative to their new employment site as well as their previous residence. Along with the usual socio-demographic variables, the analysis takes on the job search method as well as the local contacts that one has in their residential area as important variables informing these choices. The findings indicate that jobs found through the use of internet and newspapers were on average farther away from the searchers' residence as compared to those found through contacts and formal means. On relocation after employment, we find that being a renter and moving to a rental unit were important in how quickly one relocated. In addition those that used the internet to find their jobs also relocated faster after controlling for demographic variables such as age. The distribution of ones social contacts were also found to be important in how far away from the previous location a person relocated.
\end{abstract}




\section{Introduction}

The relationship between home and work locations and the commute outcomes have been a fruitful area of study for a long time. Several different approaches have been used to understand these decisions. Early models of urban structure framed location choice in the context of a mono-centric city where utility maximizing decision makers make location choices by trading off land costs with transportation costs to jobs (1). Later models have considered decentralized jobs, incorporated neighborhood preferences as well as within household tradeoffs in the selection of housing. Simpson (2) uses another framing employing spatial job choice from given residential locations. Later studies have also considered both job and residential choices from a search perspective that relates wages, place utility, and commuting costs $(3 ; 4)$. Another approach to analyze residential and employment choices has used disaggregate modeling techniques. Such models have the ability to incorporate a variety of attributes that have to do with the house, neighborhood, the individual as well as such measures as accessibility in the random utility maximizing framework. Examples include (5) and (6) among others.

This paper empirically explores the relationship between job finding and different variables that are related to relocation decisions afterwards. The connections between commute outcomes when finding a new job and the job search method that one employs are explored first. That is followed by an analysis of how long one stays at their residence after finding work, and where they eventually relocate relative to their employment site as well as their previous residence. Along with the usual socio-demographic variables, the analysis takes on the job search method as well as the local contacts that one has in their residential area as important variables informing these choices.

Different factors can influence the home-to-work distance job seekers would consider reasonable when trying to find work. Household composition, employment status at the time of search, demographics, current living conditions can all have varying degrees of influence. Renters and home owners likely have different tolerances for new commute distances. Household responsibilities can also affect what is readily accepted. Longer commutes could mean less time to spend at home, or can affect other activities that have fixed time schedules. For example, having to pick up a child from a childcare facility by a certain time can easily require the exclusion of certain locations as possible work sites without changing childcare arrangement. People who are attached to their homes or neighborhood may be reluctant to accept very long commutes when comparable employment alternatives are present at shorter commutes. Others in the same group may be willing to accept longer commutes while staying in their homes if other employment alternatives are not available to them.

In addition to such household, demographic, and economic constraints, the search path to finding employment may also play a role in the geographic location of employment. Differences in search methods are hypothesized to influence location because of the way in which information is gathered by each search medium. For instance the breadth of the search geography as well as the number of opportunities presented to the searcher when using the internet is likely to be much different from one using contacts, local newspapers, or doing walk-in applications.

Certainly, not all jobs that are found by searching the internet are farther out, and not all opportunities that are farther out are accepted. Ultimately the searcher makes the decision on what opportunities to pursue and accept. However, that certain opportunities can only be accessed (or be better accessed) by one search medium and not others given the geographic location of the searcher alters the choice set from which opportunities are pursued. It is this distinction in home-to-work distance that may arise from employing 
different search paths that we wish to uncover in the first part of this paper.

The second part of this paper looks at relocation outcomes after finding employment. Residential relocation decisions are much more deliberate than most other location decisions. These decisions can be motivated by a range of issues that have to do with changes in household structure, economic changes in the household, changes in the neighborhood etc. In addition to these factors, Clark and Withers (7) do find that job changes can also serve as a trigger to housing relocation decisions. They find the effect of a job change is especially strong for single renters and weaker in two worker households. Clark and Burt (8) also note a higher probability to relocate when the home to work distance is long.

Other factors can also influence the selection of a residential area. The demographic landscape in urban areas itself suggests that there are components to home choice that are important to the selection of one's home other than housing prices and transportation costs. There is for example considerable segregation along racial lines in the housing market in large urban areas in the US (9). Jargowsky (10) also found segregation along income lines after controlling for racial segregation. Neighborhood concentrations along age also appear to be present (11).

According to a 2004 mobility report by the Census Bureau (12), most people reported relocating due to housing related reasons $(51 \%)$ or family related reasons $(26 \%)$. Work related reason were reported as primary by $16 \%$ of respondents. A significant portion of these reported moving to a better home/apartment (20\%), moving to own a house (10\%), or a new job or transfer (9\%). The survey did not consider secondary or tertiary roles played by commute distance/time in narrowing down a location among possible alternatives. There are often many locations that can satisfy only one location consideration. In such cases, secondary reasons can play an important roles to refine the location choice.

Selection of a new location upon relocation often has to balance competing needs of the household. Commute is one part of the consideration, but it is not the only one. Giuliano and Small (13) find that the actual commute distribution is greater than what it would be expected had people made commute minimizing location choices. Using longitudinal data Clark et. al. (14) ask whether households minimize commute distance when relocating and what differences exist between one worker and two worker households. They find evidence for reducing commute distance upon relocation with increased separation. They find that the trend is higher for women and lower for two-worker households when relocating residence.

In addition to the usual demographic and commute related variables, we also study the role that job search methods as well as the spatial distribution of ones social contacts play in informing the ensuing relocation decisions. These variables can influence (either directly or indirectly) subsequent relocation decisions such as how soon relocation takes place, the new commute, and how far from their previous residence relocators move. Differences may arise because the home to work distance outcomes from some search paths maybe longer than others. They may also be a result of the implied job security because of the search medium employed. For example some research has shown employees who found their jobs through contacts to be paid more at least initially $(15 ; 16)$, and that they also have longer tenures $(16)$. The sense of security in the position that may arise from using contacts may encourage individuals to make lifestyle changes more quickly than they otherwise would. The number of contacts the relocating household has in close proximity can also influence the specifics of how far away they relocate from their previous location. People who have a large portion of their contacts in their neighborhood may not move as far away as others. Consequently they may trade closeness to these contacts by foregoing significant reductions in their commute. 


\section{Survey and Data}

Data for this study comes from a two phase web based survey that was administered to gather data on job finding, home finding, meetings that people participate and the social and technology networks that help them in these processes. Participants were recruited through mailed postcards. Postcards were sent to eight zip code areas in the Twin Cities to 5000 people in each of the two phases. The areas were chosen to have an economic and racial mix of respondents, as well as a city and suburban mix in the respondent pool. Reminder postcards were sent a week following the original mailing.

Survey participant had to be a working adults in the household. Invited respondents were asked to login to the survey with a unique code placed on the mailed postcard. The survey offered a $\$ 5.00$ coffee card to participants as well as a chance to be included in a drawing for an iPod Touch for one randomly selected respondent in each phase.

On first mailing 192 and 205 cards were returned due to wrong addresses from each phase. Overall there were 268 and 297 respondents in phase 1 and 2 respectively $(5.88 \%$ of postcards that reached their destination). The response rate for the survey was low and perhaps could have been increased by repeated solicitation to the respondents. In addition, because the questions went into the details of people's contacts and daily schedules, privacy concerns may have led some to drop out or skip questions. Availability of a computer and access to the internet in lower income areas may also have contributed to the low response rate.

Table 1 shows the distribution of demographic variables among the respondents and that for the State of Minnesota. Overall the sample shows bias towards women, and more highly educated individuals as compared to the demography of the State's population.

Table 1: Summary of Survey Subjects

\begin{tabular}{|l|l|l|l|}
\hline Variable & Group & Survey & Minnesota \\
\hline \multirow{2}{*}{ Sex } & Male & $39.8 \%$ & $49 \%$ \\
& Female & $60.2 \%$ & $51 \%$ \\
\hline $\begin{array}{l}\text { Age } \\
\text { (MN data for those between 18-65) }\end{array}$ & mean & 38.9 & 39.2 \\
\hline \multirow{2}{*}{ Household } & Renter & & \\
\hline & Owner & $22.5 \%$ & $25.4 \%$ \\
& Less than high school & $0.4 \%$ & $9.3 \%$ \\
Education & High school & $16.6 \%$ & $50.6 \%$ \\
(MN data for those 25 and older) & Associates degree & $14.1 \%$ & $9.6 \%$ \\
& Bachelor's degree & $45.7 \%$ & $20.8 \%$ \\
& Grad/Professional degree & $23.1 \%$ & $9.6 \%$ \\
\hline \multirow{2}{*}{ Household Income } & Mean & $\$ 76,550$ & $\$ 81,644$ \\
& Median & $\$ 68,000$ & $\$ 66,809$ \\
\hline \multirow{5}{*}{ Race } & White & $90.3 \%$ & $89.4 \%$ \\
& Black & $3.4 \%$ & $3.5 \%$ \\
& American Indian & $0.2 \%$ & $1.1 \%$ \\
& Asian & $3.2 \%$ & $2.9 \%$ \\
& Other & $3.0 \%$ & $3.1 \%$ \\
\hline
\end{tabular}




\section{Analysis}

where:

Broadly speaking, the survey focused on four areas. The first section dealt with the experience of the respondent during their last job search. Respondents were asked how they found their job, including whether contacts were used, and if so, details on the contact. The second section dealt with their residence, including when they moved and what their reasons for moving were, the third section dealt with the respondent's social network and what their weekly social meeting looks like. The survey ends with questions about the respondent's commute and demographics.

\section{Employment Search and Commute Outcomes}

To uncover the relationship between search path and commute outcomes, the current home-to-work distance and travel time are modeled as a function of whether the respondent owns or rents their current residence, the method of job finding, the age of the person when taking the job, and the number of years they had spent in their residence at the time of taking the job.

This model is applied to individuals who have not yet relocated after finding their current work. This would mean individuals who have relocated because their commute was onerous for example would be excluded. If indeed particular search paths were associated with some paths, it would make this model conservative it its estimation. Dummy variables are also used to control for different suburban home locations. The proposed model is as follows:

$$
D_{h w} \sim f\left(R_{c}, J_{f}, J_{i}, J_{n}, I, A_{j}, E, H, Y_{h j}, N W, S E\right)
$$

$$
T_{h w} \sim f\left(R_{c}, J_{f}, J_{i}, J_{n}, I, A_{j}, E, H, Y_{h j}, N W, S E\right)
$$

$D_{h w}:$ Home-to-work distance (dependent variable for model 2)

$T:$ Home-to-work travel time (dependent variable for model 3)

$R_{c}$ : Do you currently rent your residence? (yes $=1$ )

$J_{f}:$ Job found through formal means

$J_{i}:$ Job found through the Internet

$J_{n}:$ Job found through newspaper ads

$A_{j}:$ Age at the time of taking job

$Y_{h j}:$ Number of years at current residence at the time of taking the job

$N W$ : Dummy variable for home location in the north west suburbs of the Twin Cities

$S W$ : Dummy variable for home location in the south/south east suburbs of the Twin Cities

The estimated model is given in Tables 2 and 3. 
In the distance model (Table 2), the variables of household income, age at the time of taking the job and household size are not significant and do not explain the variability in the data. As hypothesized, among those who have not yet relocated after finding work, the renters live farther from the employment location than do home owners. This is likely because renters can relocate easily to new locations, and can adjust their travel time at the time of relocation.

Job seekers that used the internet and the newspaper to find work both have longer home-to-work distances than do those that used formal means and contacts ( $\mathrm{p}=.064$ and $\mathrm{p}=.055$ respectively). This is likely due to the variety of information that is gathered by the internet and newspaper. Whereas a recruiter can specialize in one geographic area, or be told to look for opportunities in a particular area, identifying these locations while using the internet or newspaper would require the searcher to sift through information personally and could bring new opportunities to the fore. The mean home-to-work distance for internet users is higher by 2.4 miles and for those using newspaper, it is higher by 3.3 miles. The possibility that using formal means was more suited to one type of area over the other was tested using the data (for example the CBD and using recruiters etc.) but no association was found between search path and distance of the employment location from the CBD.

The other variable that was significant was the dummy for the northwest suburb. Respondents living in this area reported higher home-to-work distance than respondents in the City of Minneapolis or in the southeast suburbs. The reason is likely related to the thinner job density in these locations relative to the center and southern parts of the metro area. Home tenure before finding the new work location has the expected negative sign, indicating those that have lived in their homes (and neighborhood) longer opted for closer work opportunities $(\mathrm{p}=0.107)$.

Looking at the travel time model (Table 3), though the signs and tendencies exhibited by the model estimates are similar to those in the distance model, many of the statistical significances are absent. For example internet and newspaper users still have positive relationship with travel time ( $\mathrm{p}=0.256 \& \mathrm{p}=0.122$ respectively), renters show a higher travel time than owners $(\mathrm{p}=0.156)$ and those in the northwestern suburbs report higher travel times $(\mathrm{p}=0.139)$. While distance and travel time are correlated, travel time depends on variables such as capacity and demand on the routes between home and work, and in some cases places that are farther can be reached much faster than places that are geographically closer due to differences in demand and capacity.

Overall, the distance model suggests that job finding paths have unique characteristics that would lead to different home-to-work distances. The use of contacts and formal means such as recruiters leads to locations that are on average closer to the searcher than do using the internet or newspaper. On the other hand, based on our data this distinction in distance is not reflected in the travel time data though the trends are similar.

The differences in distance along with other household demographic and economic constraints can influence relocation decisions or the location decisions once the decision to relocate has been made. To study the possible relationships between job finding and decisions of residence afterwards (stay/move, stay for how long, and if moving to where?) the next section will focus on the survey participants that have relocated their residence since finding their current work. 
Table 2: Home-to-work distance (miles) after finding new work

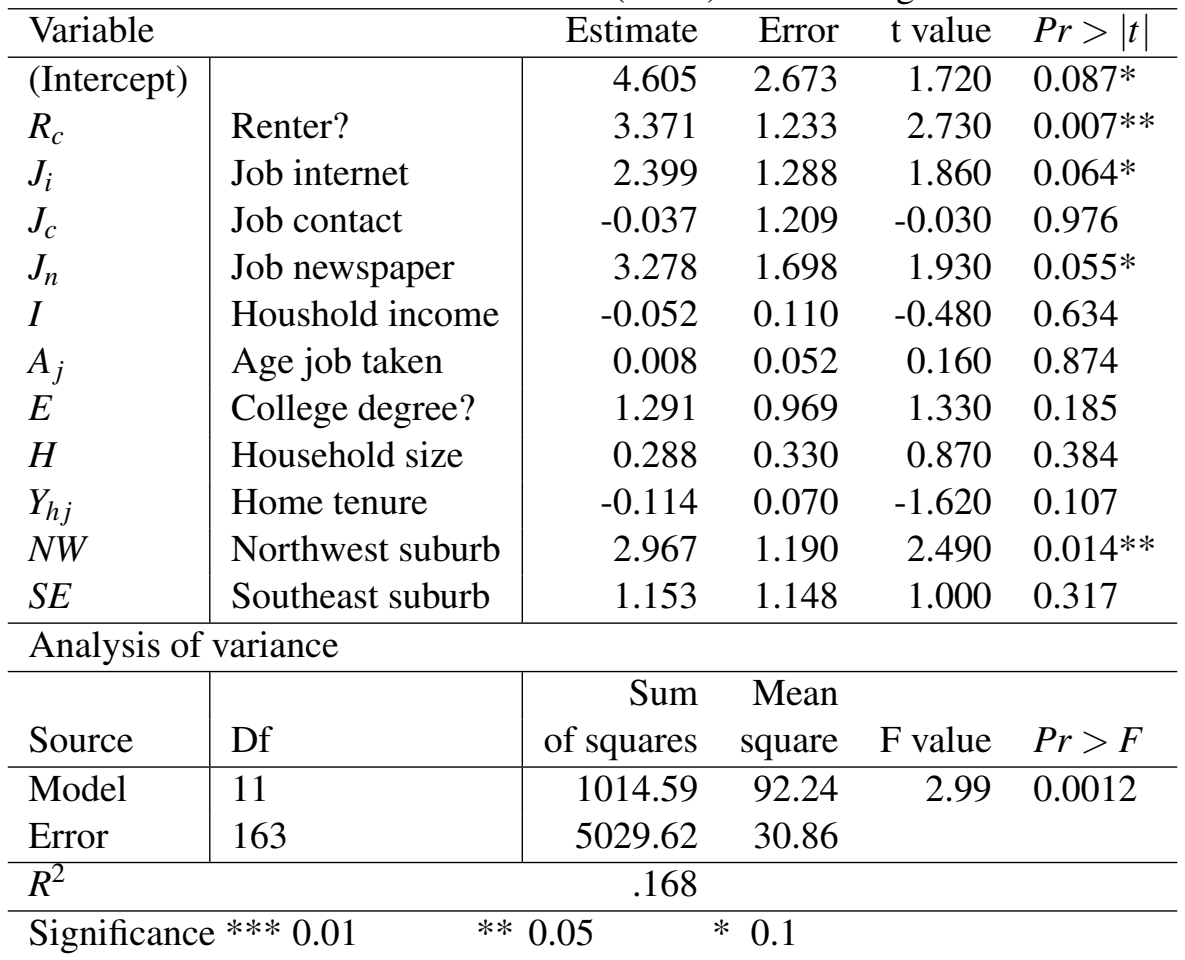

\section{Commute Outcomes of Relocation After Finding Employment}

This section looks at commute outcomes of relocation that occurs after finding work. Residential relocation decisions can be motivated by a variety of factors from changes in household structure to employment and economic changes in the household. The primary, secondary and tertiary relocation reasons cited among all respondents in the survey are given in table 4 . The primary reasons most often cited by the respondents are cost of the unit and affordability of the area followed by closeness to work and closeness to family and friends. Aggregated together home and neighborhood related reasons make up a majority of the reasons cited. "Being close to work" is cited frequently as one of the top three reasons for relocation with $36.7 \%$ of respondents whose previous home was in the metropolitan area of the Twin Cities selecting it. Figure 1 shows the previous-home-to-work and current home-to-work distances. It is clear that many maintain or reduce their commute distance upon relocation. The figure also shows that most of those that cited commute as a reason for relocating did reduce their home-to-work distance from what it would have been had they not relocated.

Other studies have also shown that many household maintain their commute upon relocation. In a case study of the housing changes of employees at a Southern California firm (17). The authors find that trip lengths of the employees did not increase substantially over a period of six years. The stability of travel times over a long period of time is observed as the employment landscape in major metropolitan areas has been changing by suburbanizing jobs and housing. This stability has been explained as arising from rational location decisions both by firms and individuals to keep travel time constant (18). Increasing accessibility that arises from jobs that have followed suburbanizing homes has also helped create this stability (19). 
Table 3: Home-to-work travel time (minutes) after finding new work

\begin{tabular}{|c|c|c|c|c|c|}
\hline Variable & & Estimate & Error & $\mathrm{t}$ value & $\operatorname{Pr}>|t|$ \\
\hline (Intercept) & & 12.283 & 3.464 & 3.55 & $0.001 * * *$ \\
\hline$R_{c}$ & Renter? & 2.286 & 1.605 & 1.42 & 0.156 \\
\hline$J_{i}$ & Job internet & 1.901 & 1.666 & 1.14 & 0.256 \\
\hline$J_{c}$ & Job contact & -0.251 & 1.556 & -0.16 & 0.872 \\
\hline$J_{n}$ & Job newspaper & 3.449 & 2.218 & 1.56 & 0.122 \\
\hline$I$ & Houshold income & -0.099 & 0.141 & -0.7 & 0.485 \\
\hline$A_{j}$ & Age job taken & 0.029 & 0.067 & 0.44 & 0.659 \\
\hline E & College degree? & 1.311 & 1.254 & 1.05 & 0.297 \\
\hline$H$ & Household size & 0.049 & 0.430 & 0.11 & 0.909 \\
\hline$Y_{h j}$ & Home tenure & -0.175 & 0.090 & -1.95 & $0.053 * *$ \\
\hline$N W$ & Northwest suburb & 2.283 & 1.536 & 1.49 & 0.139 \\
\hline$S E$ & Southeast suburb & -0.969 & 1.475 & -0.66 & 0.512 \\
\hline \multicolumn{6}{|c|}{ Analysis of variance } \\
\hline Source & Df & $\begin{array}{r}\text { Sum } \\
\text { of squares }\end{array}$ & $\begin{array}{r}\text { Mean } \\
\text { square }\end{array}$ & $\mathrm{F}$ value & $\operatorname{Pr}>F$ \\
\hline Model & 11 & 953.65 & 86.70 & 1.7 & 0.077 \\
\hline Error & 161 & 8201.93 & 50.94 & & \\
\hline \multicolumn{2}{|l|}{$R^{2}$} & \multicolumn{2}{|l|}{.104} & & \\
\hline
\end{tabular}

Relocation after finding employment can be an immediate or long term consideration. How soon relocation takes place can depend on the circumstances of the relocators' residence (rent/own, location etc.) and life style and household characteristics at the time of employment as well as the characteristics of the new employment. For instance a renter who found employment farther from their rental unit may find it easier to relocate to accommodate the new commute than a home owner due to the costs involved. Larger households, or dual earner households may find it more difficult to relocate while reasonably meeting the needs of the household. A person planning to buy a house next may find the costs of immediate relocation not worth any of the benefits relocation provides. Those who like their neighborhood, or have numerous local friends may opt to not relocate or relocate closer to their previous location while achieving the other goals of relocation. Age, income, household size and so on which influence the lifestyle of the decision makers can also have impacts on relocation considerations.

The last section showed the relationship between commute distance and job finding methods. As discussed in the introduction, search methods can influence relocation decisions due to this and the intermediary roles played by contacts that may give implicit assurances of security in a new employment that lead to quicker changes.

Among the competing considerations that relocating households have, it is hypothesized that individuals with larger social contacts in their neighborhood are less likely to move, or when they move they are more likely to move shorter distances away from where they were as compared to those that have fewer contacts in close proximity. Alternately as well individuals that have a large circle of close contacts around the metropolitan area are expected to relocate more freely.

21 In this section, we hope to uncover the relationships between job finding, tenure before relocation, new 


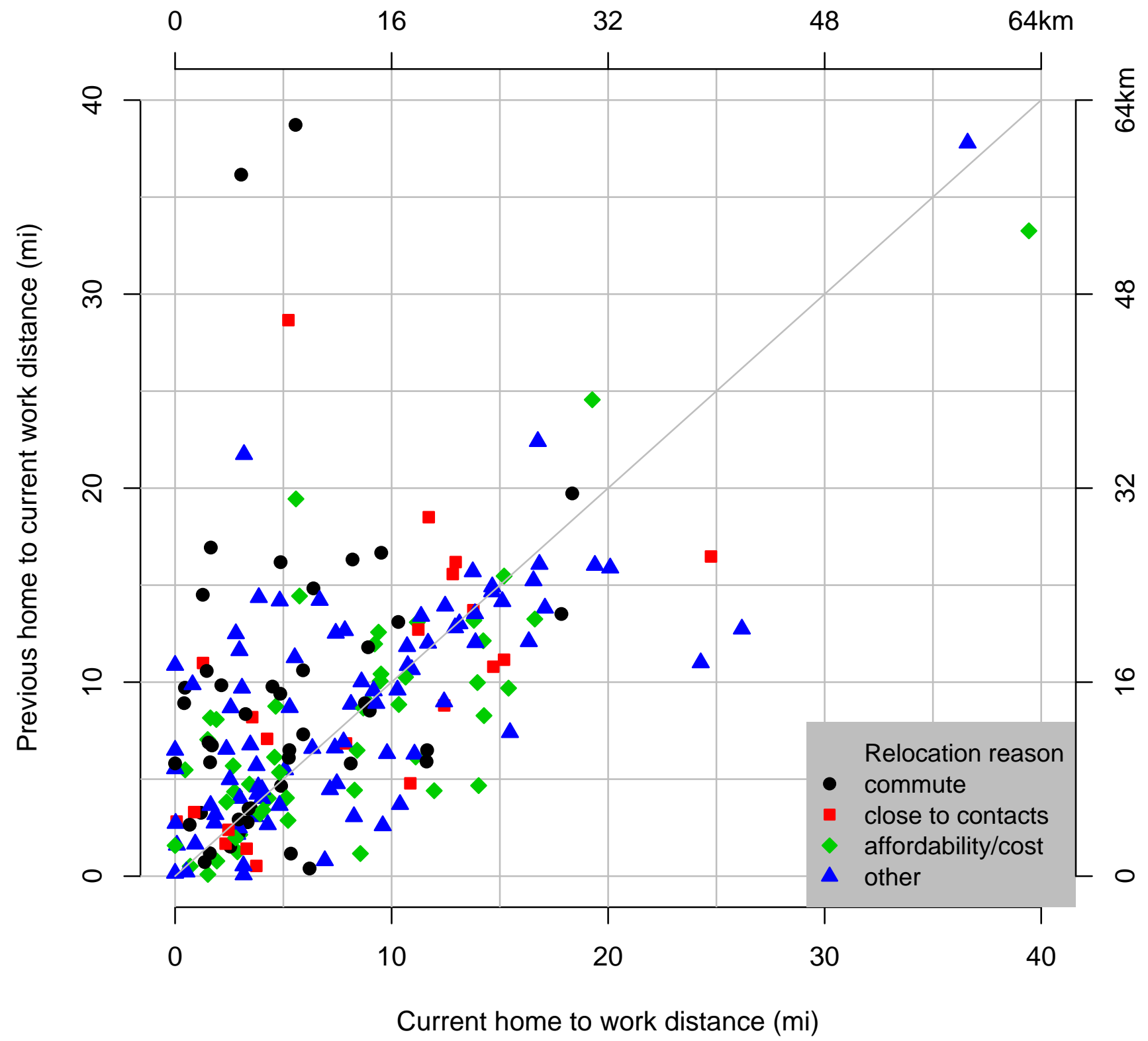

Figure 1: Distance between home and work before and after relocation for individuals who have relocated since finding their current work. 
Table 4: Top three reasons for relocation among those whose previous home was in the Twin Cities metropolitan area (percentages)

\begin{tabular}{l|rrr}
\hline & Reason 1 & Reason 2 & Reason 3 \\
\hline Cost of living/affordability & 27.89 & 21.09 & 13.83 \\
Close to work & 17.01 & 12.93 & 8.16 \\
Close to family/friends & 10.43 & 12.47 & 7.94 \\
Bike friendly area & 0.23 & 1.36 & 2.49 \\
Close to transit & 1.13 & 2.49 & 2.27 \\
Close to the city & 14.74 & 14.06 & 12.7 \\
Close to church & 0.91 & 2.04 & 1.13 \\
Close to open spaces & 2.95 & 6.58 & 8.62 \\
Larger lot size & 1.59 & 1.81 & 3.17 \\
Away from the city & 0.68 & 0.23 & 0.91 \\
Residence unit features & 7.94 & 5.44 & 6.35 \\
Safety & 1.81 & 3.17 & 3.63 \\
Kid friendly neighborhood & 1.36 & 3.4 & 5.67 \\
Good school district & 3.17 & 2.04 & 2.72 \\
Investment value of home & 2.27 & 3.4 & 6.35 \\
Other & 2.04 & 1.81 & 1.36 \\
Unreported & 3.85 & 5.67 & 12.7 \\
\hline Count & \multicolumn{3}{|}{441} \\
\hline
\end{tabular}

commute and how far away people relocate from their previous location using variables reported from the survey discussed above. The influence of job finding methods, social contacts, household and personal variables and the interdependence between how long after job finding the person relocates, the new locations distance from the previous home and the new commute are explicitly considered. The relationship between these variables can be studied using path analysis.

Relocation decisions after finding new employment are hypothesized to take time after finding work during which time a household stayed in their previous residence. This time is expected to be influenced by the persons' living arrangement, how they found their job, their age, what kind of move they aim to make, as well as their commute to the new work location. Younger individuals, as well as renters are expected to relocate faster. Individuals who aim to rent next are also expected to move sooner than those who aim to purchase their next residence. The longer their commute to their new employment, the quicker individuals are expected to relocate. If the job was found through a contact, relocation is expected to occur sooner because of the implied confidence in the security of the new job. Individuals who found their job through the use of internet and newspaper are also expected to relocate sooner relative to those using formal means.

In choosing their new location, individuals with smaller households are expected to be able to lower their commute than those with larger households who have to balance competing commute and location requirements. Those with larger incomes are expected to be motivated by other considerations such as larger homes and lot sizes which imply locations farther out from employment centers, and hence longer commutes.

Individuals whose commutes become longer when finding new employment are expected to lower or maintain their previous home-to-work distance upon relocation. In addition, those individuals who relocate sooner are expected to lower their commute than those that stay at their current location under the new com- 
mute. In this arrangement, the commute right after relocation is expected to impact the new home-to-work distance directly, and indirectly through their tenure at their previous location.

Another consideration in relocation is also how far away from their current neighborhood a household relocates. Naturally the longer they have lived in the neighborhood, the more they know about it relative to other areas and the more attached they would be to it. How far away relocation occurs in this case is expected to be negatively impacted by home long after finding work, the relocation takes place.

In addition, the number of contacts a person has in their neighborhood can negatively influence how far away they relocate if closeness to these contacts is important to them. Alternately if an individual has a large number of contacts spread across the metropolitan area, it could mean that they have opportunities to relocate at locations that are farther from their current neighborhood while maintaining closeness to a desirable number of their contacts. The number of contacts a person has and the percentage of contacts in a 3 mile radius after relocation are used as indicator variables to how many local and total contacts the respondents had at their previous location.

The complexity in the tradeoffs as well as the time precedence in the different decisions involved in relocation require an analysis framework that looks at the interrelationships between variables holistically. Path analysis is employed in this section to study these relationships. The hypothesized relationships between individual characteristics, job search, tenure at home, commuting distance, and different outcomes of the relocation decision is shown in figure 2.

Path analysis has its origins in biology in the work of Sewall Wright $(20 ; 21 ; 22 ; 23)$. Wright first used the method in linking the degree to which heredity and environment affect the color of guinea-pigs' offsprings (20). Wright (24) describes path analysis as:

"...a way of dealing with interrelated variables. It is based on the construction of qualitative diagram in which every included variable, measured or hypothetical, is represented (by arrows) either as completely determined by certain others (which may be represented as similarly determined) or as an ultimate factor."

The method is one where a hypothesized set of relationships that are dependent on one another can be tested. Path models employ both standardized and absolute (measured) variables in estimation. For the standardized estimates, each of the variables is adjusted so that its mean is zero and its standard deviation is equal to one. The standardized estimates of the path model give how many standard deviations the endogenous variable moves in response to a change in one standard deviation of the exogenous variable when all other variables are held constant. The regression coefficients, estimated from the observed variables, measure the contribution of each of the independent variables on the dependent variables. The method has often been called causal modeling, however, as Denis and Legerski (25) point out the case for causality has to lie outside of the statistical modeling technique. Miller (26) summarizes the assumptions behind path models.

The path model shown in figure 2 encapsulates decisions taken over a long period of time. Job finding is the earliest event, and relocation is the latest event. These are separated by the tenure at the previous location after finding the current job. The age at which the current job was found and the years spent at the previous home add up to make the age at relocation. The new home-to-work distance and the previous home-to-current-home distance are outcomes of the latest decision.

In light of these time differences it is essential to establish which variables are from the time of the decision and which are not. Household size, household income, and household vehicles are from the time of the 
survey, and should be taken as indicator variables of lifestyle at the time of the decision. Just over 54\% of the relocations considered here have occurred since January of 2004, and a further 20\% since 2000. The number of contacts $\left(C_{s}\right)$ and the percentage of contacts within three miles of home $\left(C_{p 3}\right)$ are variables reported as of the time of the survey, and these should be considered as indicator variables of how many total close contacts a person has and how many of those are in close proximity to them.

A path model was estimated for the relationships proposed in figure 2 using the CALIS procedure of SAS software (27). The final estimated model is shown in figure 3. Many of the hypothesized relationships hold while a few are found to be not relevant or having the opposite direction.

Contrary to what was expected, older individuals relocated faster than younger individuals. For each additional year a person is older when taking a new job, tenure at their older home decreased by $1.98 \%$. Individuals that would relocate to a rental unit spend $27 \%$ less time at their residence than people who purchase their next location, and those that were renting their residence at the time of finding work relocate $36 \%$ sooner than home owners. Owners are more committed to their residences, and the costs of relocation are much higher to them than to renters. Those who plan to own also take longer to relocate because the home search takes planning and time. Since home ownership involves risks that renters do not endure, getting into the "right" home can be a more deliberate process.

\begin{tabular}{rrrrrr}
\multicolumn{6}{c}{ Table 5: Goodness of Fit of Measures } \\
& Chi-squared & df & p & NFI & NNFI \\
\hline Null Model & 333.16 & 78 & 0.000 & - & - \\
Estimated Model & 15.10 & 19 & 0.716 & 0.955 & 1.063 \\
\hline
\end{tabular}

Those who found their job through the internet stayed the least amount of time at their residence when finding a new job. Since the trend for internet users persists even after controlling for age and distance, there may be unseen variables among those that use the internet to find jobs that makes them footloose and less attached to their residential location. Those who used contacts have the anticipated direction, but the magnitude is less than that for internet users, and statistically it is not significant. The estimate for newspaper users is as anticipated, but it too is not statistically significant.

These observed variables have direct and indirect impacts on the home-to-work distance after relocation $(D)$ and how far away from their current home individuals relocate $\left(D_{h h}\right)$. The home-to-work distance after relocation depends weakly on how soon the relocation occurred, but is strongly related to what the commute distance before relocation was, and with household income. Each percentage increase in "previous hometo-work distance' are is positively related to the new home-work-distance. It suggests that those who had tolerated longer commutes before, will tolerate them still after a move.

Though not statistically significant, the model also suggests that those who experienced the previous hometo-work distance for a longer period of time after finding their work also had longer commutes. This is consistent with the idea that those who do not relocate quickly relocate for reasons other than commute. A household's income also plays a role in the home-to-work relocation after a move. With each $\$ 1,000$ increase in household income, the new home-to-work distance increases by $2.7 \%$. This is consistent with our hypothesis that wealthier households might be concerned about other aspects that are not commute related. No direct relationship was found between being household size and home-to-work distance.

In choosing the new neighborhood, another factor that is considered is how far away the person moves from their previous neighborhood. The $D_{h h}$ variable measures this distance. As hypothesized earlier, an important 


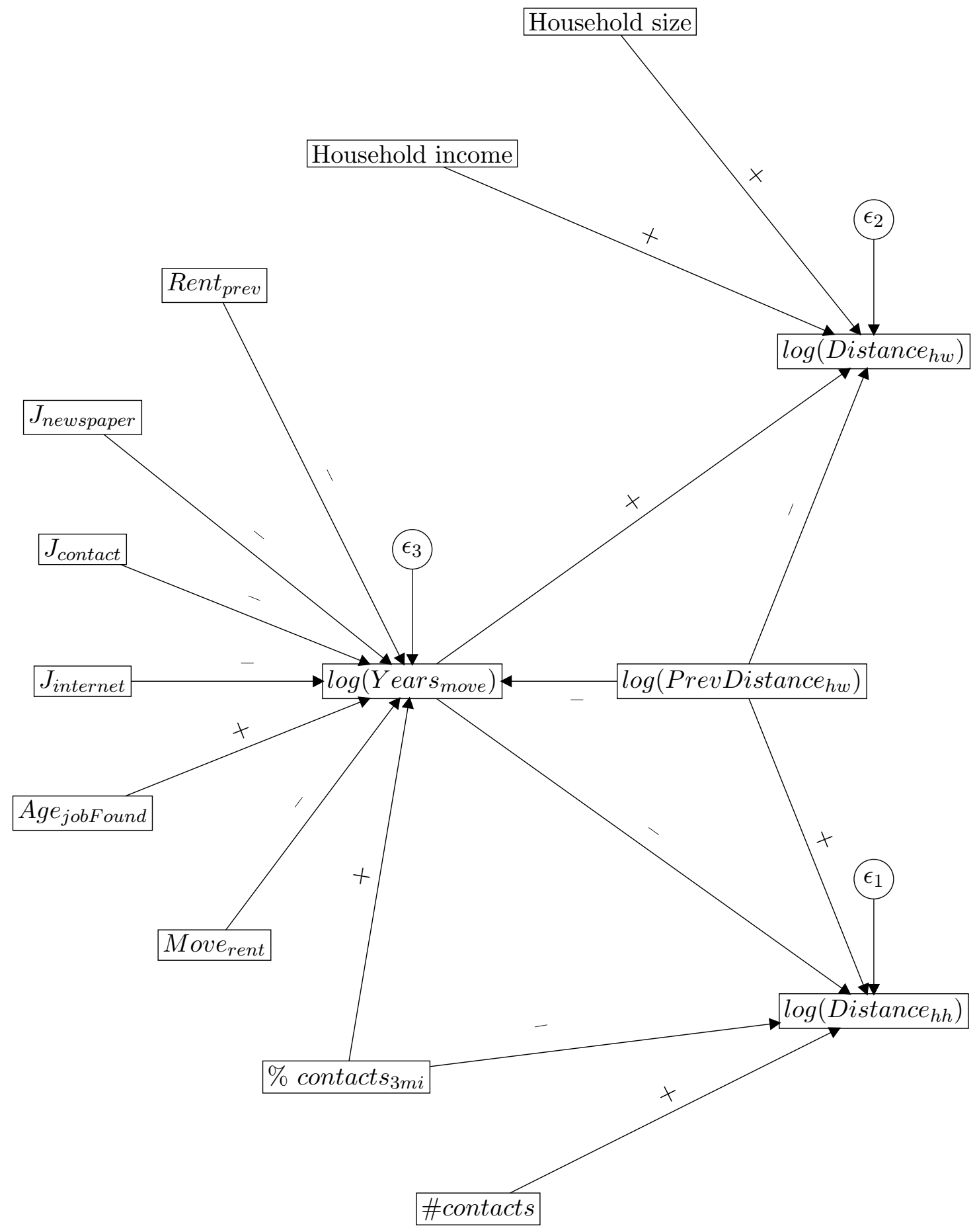

Figure 2: Proposed path model of tenure, commute, and moving distance after finding employment (correlations between exogenous variables not shown.) 


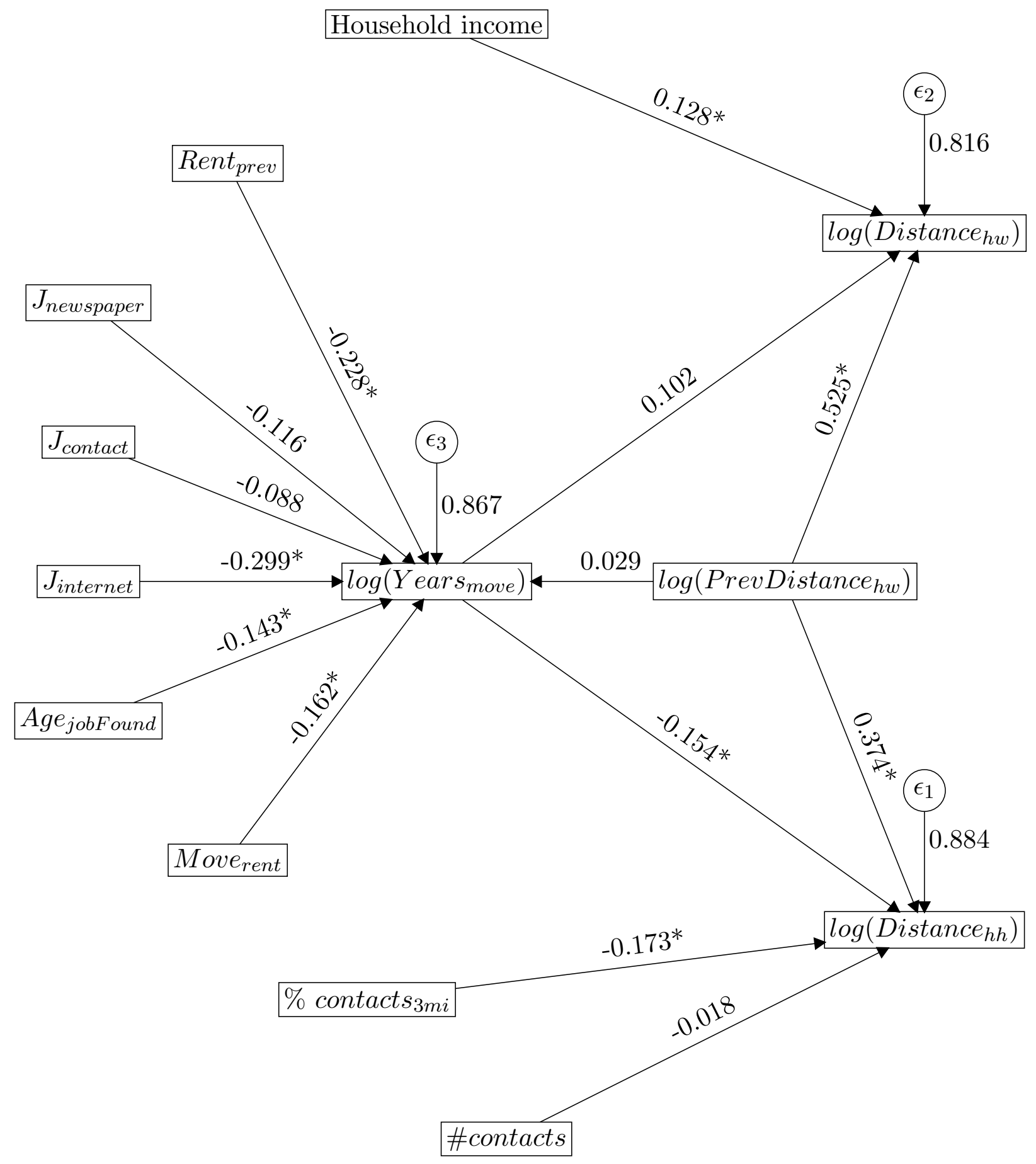

Figure 3: Estimated path model of tenure, commute, and moving distance after finding employment (correlations between dependent variables not shown. See Table 7). Estimates that are significant at the .05 level are marked with $\mathrm{a} *$. ) 
Table 6: Estimated path model for relocation after finding work

\begin{tabular}{|c|c|c|c|c|c|}
\hline & & Variable & Estimate & Std. Error & t-stat \\
\hline \multirow{10}{*}{$\begin{array}{l}\text { Time between } \\
\text { finding } \\
\text { work and } \\
\text { relocation } \\
\left(\log \left(Y_{m v}\right)\right)\end{array}$} & Distance before move & $\log \left(D_{p}\right)$ & 0.030 & 0.070 & 0.43 \\
\hline & Job through contact & $J_{c}$ & -0.155 & 0.135 & -1.14 \\
\hline & Job through internet & $J_{i}$ & -0.875 & 0.198 & -4.41 \\
\hline & Job through newspaper & $J_{n}$ & 0.278 & 0.180 & 1.55 \\
\hline & Age job taken & $A_{j}$ & -0.020 & 0.010 & -2.06 \\
\hline & Moving to rental? & $R_{c}$ & -0.317 & 0.149 & -2.13 \\
\hline & Rented before move? & $R_{p}$ & -0.444 & 0.142 & -3.12 \\
\hline & Error variance & & 0.555 & & \\
\hline & Total variance & & 0.740 & & \\
\hline & $R^{2}$ & & 0.249 & & \\
\hline \multirow{6}{*}{$\begin{array}{l}\text { Commute } \\
\text { distance } \\
\text { after move } \\
(\log (D)) \\
\end{array}$} & Years to move & $\log \left(Y_{m v}\right)$ & 0.103 & 0.064 & 1.59 \\
\hline & Distance before move & $\log \left(D_{p}\right)$ & 0.541 & 0.066 & 8.17 \\
\hline & Household income (1000) & $I$ & 0.027 & 0.014 & 1.97 \\
\hline & Error variance & & 0.499 & & \\
\hline & Total variance & & 0.750 & & \\
\hline & $R^{2}$ & & 0.335 & & \\
\hline \multirow{7}{*}{$\begin{array}{l}\text { Previous to } \\
\text { new home } \\
\text { distance } \\
\left(\log \left(D_{h h}\right)\right)\end{array}$} & Years to move & $\log \left(Y_{m v}\right)$ & -0.164 & 0.073 & -2.24 \\
\hline & Distance before move & $\log \left(D_{p}\right)$ & 0.406 & 0.076 & 5.32 \\
\hline & Num. of contacts $(/ 10)$ & $C$ & -0.009 & 0.036 & -0.26 \\
\hline & $\%$ of contacts in $3 \mathrm{mi}$ & $C_{p 3}$ & -0.009 & 0.004 & -2.46 \\
\hline & Error variance & & 0.655 & & \\
\hline & Total variance & & 0.837 & & \\
\hline & $R^{2}$ & & 0.218 & & \\
\hline
\end{tabular}

consideration for how far people moved from their previous location is assumed to be neighborhood quality as well as the contacts that they would leave behind. The model shows that those that didn't relocate as quickly did not relocate farther. For each additional year stayed at the home before relocation, the previous home to new home distance reduces by $1.6 \%$.

Another important variable that indicates how far a person moves is the percentage of contacts that live around them. Here the role of contacts is clear. The model suggests that the for each percentage gain in the proportion of close contacts in a 3 mile radius, the relocation distance from their previous home is reduced by $0.9 \%$. The significance of the relationship supports the hypothesis that the people who have a larger proportion of their contacts close by stayed close to those contacts when moving.

\section{Summary}

This paper looked at commuting outcomes of job finding, and the commuting outcomes of relocations. One of the hypothesis that was tested is that job search methods can impact the commute distance because of the ways in which information is gathered. Specifically it was hypothesized that jobs found through internet 
Table 7: Correlations among exogenous variables for relocation after finding work (only those above 0.1 reported)

\begin{tabular}{|l|l|r|}
\hline Variable 1 & Variable 2 & Correlation \\
\hline$A_{j}$ & $C$ & 0.159 \\
$A_{j}$ & $C_{p 3}$ & 0.126 \\
$A_{j}$ & $R_{p}$ & -0.215 \\
$R_{c}$ & $R_{p}$ & 0.258 \\
$I$ & $R_{c}$ & -0.285 \\
$I$ & $R_{p}$ & -0.253 \\
$J_{c}$ & $I$ & 0.107 \\
$J_{c}$ & $C_{p 3}$ & 0.138 \\
$J_{c}$ & $R_{p}$ & -0.122 \\
$J_{i}$ & $A_{j}$ & -0.178 \\
$J_{i}$ & $R_{c}$ & 0.277 \\
$J_{i}$ & $I$ & -0.141 \\
$J_{i}$ & $R_{p}$ & 0.173 \\
$\log \left(D_{p}\right)$ & $I$ & 0.184 \\
$\log \left(D_{p}\right)$ & $J_{i}$ & 0.109 \\
$\log \left(D_{p}\right)$ & $C$ & -0.112 \\
$\log \left(D_{p}\right)$ & $C_{p 3}$ & -0.192 \\
$C$ & $R_{c}$ & -0.169 \\
$C$ & $R_{p}$ & -0.131 \\
$C_{p 3}$ & $R_{c}$ & -0.141 \\
$C_{p 3}$ & $R_{p}$ & -0.169 \\
\hline
\end{tabular}

searches would be on average farther out than traditional methods. The findings from the first part of this paper support this hypothesis. In addition it was also found that commute distances from newspaper found jobs were also longer than jobs found through formal means or contacts.

The relationship between job search, tenure, relocation, and social networks was also studied using path analysis. The findings suggest that relocation costs (renting before, and moving to a rental) were instrumental in how quickly individuals relocated after finding their work. Job searchers who used the internet to find their current employment also relocated faster reinforcing the hypothesis from the first section of the analysis.

Though jobs found through contacts did not show particular patterns in regards to tenure, other social network variables were found important in the relocation choice. The percentage of contacts that are within a 3 mile radius of a person (self reported) has a negative relationship with how far away one relocates. This suggests that social networks have an influence location decisions. This role, though essential from the decision makers perspective, may limit the reductions in commute that may be achieved through relocation. 
Table 8: Overall and indirect effects of exogenous variables on relocation, commute and tenure

\begin{tabular}{|l|r|r|r|r|r|}
\hline & \multicolumn{3}{|c|}{ Overall effect } & \multicolumn{2}{c|}{ Indirect effect } \\
\hline & $\log (D)$ & $\log \left(D_{h h}\right)$ & $\log \left(Y_{m v}\right)$ & $\log (D)$ & $\log \left(D_{h h}\right)$ \\
\hline $\log \left(D_{p}\right)$ & 0.544 & 0.401 & 0.030 & 0.003 & -0.005 \\
$J_{c}$ & -0.016 & 0.025 & -0.155 & -0.016 & 0.025 \\
$J_{i}$ & -0.081 & 0.13 & -0.792 & -0.081 & 0.130 \\
$J_{n}$ & 0.029 & -0.046 & 0.278 & 0.029 & -0.046 \\
$A_{j}$ & -0.002 & 0.003 & -0.020 & -0.002 & 0.003 \\
$I$ & 0.027 & 0 & 0 & 0 & 0 \\
$C$ & 0 & -0.009 & 0 & 0 & 0 \\
$C_{p 3}$ & 0 & -0.009 & 0 & 0 & 0 \\
$R_{c}$ & -0.034 & 0.054 & -0.329 & -0.034 & 0.054 \\
$R_{p}$ & -0.046 & 0.073 & -0.448 & -0.046 & 0.073 \\
$\log \left(Y_{m v}\right)$ & 0.102 & -0.164 & 0 & 0 & 0 \\
\hline
\end{tabular}

\section{References}

[1] W Alonso. Location and Land Use: Toward a General Theory of Land Rent. Harvard University Press, Cambridge, Mass., 1964.

[2] W Simpson. A simultaneous model of workplace and residential location incorporating job search. Journal of Urban Economics, Jan 1980.

[3] Jos van Ommeren. On-the-job search behavior: The importance of commuting time. Land Economics, 74(4):526-540, 1998.

[4] Jos van Ommeren, Piet Rietveld, and Peter Nijkamp. Job moving, residential moving, and commuting: A search perspective. Journal of Urban Economics, 46(2):230-253, 1999.

[5] P. Waddell. Accessibility and residential location: the interaction of workplace, residential mobility, tenure, and location choices. In Lincoln Land Institute TRED Conference., 1996.

[6] J Abraham and J Hunt. Specification and estimation of nested logit model of home, workplaces, and commuter mode choices by multiple-worker households. Transportation Research Record: Journal of the Transportation Research Board, Jan 1997.

[7] W Clark and S Davies Withers. Changing jobs and changing houses: Mobility outcomes of employment transitions. Journal of Regional Science, Jan 1999.

[8] W Clark and James Burt. The impact of workplace on residential relocation. Annals of the Association of American Geographers, pages 59-67, Mar 1980.

[9] Douglas S. Massey and Nancy A. Denton. Hypersegregation in u.s. metropolitan areas: Black and hispanic segregation along five dimensions. Demography, 26(3):373-391, 1989.

[10] Paul A. Jargowsky. Take the money and run: Economic segregation in u.s. metropolitan areas. American Sociological Review, 61(6):984-998, 1996. 
[11] Albert Chevan. Age, housing choice, and neighborhood age structure. American Journal of Sociology, $87: 1113-1149,1982$.

[12] Jason P. Schachter. Geographical mobility: 2002 to 2003. Technical report, US Census Bureau, Washington, D.C., March 2004.

[13] G Giuliano and K Small. Is the journey to work explained by urban structure? Urban Studies, Jan 1993.

[14] W Clark, Y Huang, and S Withers. Does commuting distance matter? commuting tolerance and residential change. Regional Science and Urban Economics, Jan 2003.

[15] D.T. Mortensen and T. Vishwanath. Personal contacts and earnings. It is who you know! Labour Economics, 1(2):187-201, 1994.

[16] Curtis J. Simon and John T. Warner. Matchmaker, matchmaker: The effect of old boy networks on job match quality, earnings, and tenure. Journal of Labor Economics, 10(3):306-330, 1992.

[17] Martin Wachs, Brian D. Taylor, Ned Levine, and Paul Ong. The Changing Commute: A Case-study of the Jobs-Housing Relationship over Time. Urban Stud, 30(10):1711-1729, 1993.

[18] D Levinson and A Kumar. The rational locator: Why travel times have remained stable. Journal of the American Planning Association, Jan 1994.

[19] D Levinson. Accessibility and the journey to work. Journal of Transport Geography, Jan 1998.

[20] S Wright. The relative importance of heredity and environment in determining the piebald pattern of guinea-pigs. Proceedings of the National Academy of Sciences, 6:320-332, 1920.

[21] S Wright. Correlation and causation. Journal of Agricultural Research, Jan 1921.

[22] S Wright. The theory of path coefficients a reply to niles's criticism. Genetics, Jan 1923.

[23] S Wright. The method of path coefficients. The Annals of Mathematical Statistics, 5(3):161-215, 1934.

[24] Sewall Wright. Path coefficientes and path regressions: Alternative or complementary concepts? In Hubert M. Blalock, editor, Causal Models in the Social Sciences, chapter 3, pages 39-53. Aldine Transaction, 1985. Reproduced from S. Wright, "Path Coefficientes and Path Regressions: Alternative or Complementary Concepts?” Biometrics 16 (1960).

[25] D Denis and J Legerski. Causal modeling and the origins of path analysis. Theory \& Science, Jan 2006.

[26] M Miller. Potentials and pitfalls of path analysis: A tutorial summary. Quality and Quantity, Jan 1977.

[27] SAS Institute Inc. Sas 9.1.3. Cary, NC, 2000-2004. 